\title{
EVALUASI KINERJA STRUKTUR JEMBATAN PELENGKUNG AKIBAT BEBAN GEMPA DENGAN ANALISIS RIWAYAT WAKTU
}

\author{
(Evaluation of the Performance of Arch Bridge Structures due to Earthquake Loads with \\ Time History Analysis)
}

\author{
Widya Apriani ${ }^{1}$, Fadrizal Lubis ${ }^{1}$, Reni Suryanita ${ }^{2}$, Afrialdi $^{1}$ \\ ${ }^{1}$ Program Studi Teknik Sipil Universitas Lancang Kuning \\ ${ }^{2}$ Jurusan Teknik Sipil Universitas Riau \\ E-mail: widyaapriani@unilak.ac.id
}

Diterima 2 Oktober 2020, Disetujui 27 Oktober 2020

\begin{abstract}
ABSTRAK
Perilaku struktur jembatan pelengkung memiliki kekhasan tersendiri dalam menyalurkan pembebanan. Bentuk melengkung dari struktur memungkinkan berat sendiri struktur disalurkan ke pondasi sebagai gaya normal tekan tanpa lenturan . beban disalurkan melalui struktur setengah lingkaran menuju abutmen di kedua sisinya. Desain pelengkung (setengah lingkaran) secara alami akan mengalihkan beban yang diterima lantai kendaraan jembatan menuju ke abutmen yang menjaga kedua sisi jembatan agar tidak bergerak kesamping. Gempa merupakan pembebanan siklik yang dominan horizontal terhadap suatu struktur. Kinerja struktur jembatan akibat efek pembebanan gempa menjadi aspek penting yang perlu diperhitungkan dalam mendesain dan mengevaluasi struktur jembatan. Metode yang digunakan dialam kajian ini adalah analisis riwayat waktu. Artikel ini bertujuan untuk mengevaluasi kinerja struktur jembatan pelengkung akibat beban gempa dengan metode analisis riwayat respons gempa (time hystory analysis). Hasil Kinerja struktur menunjukkan bahwa. kinerja jembatan akibat pembebanan gempa Loma prieta di hasilkan dari skala periode yang telah dianalisis dengan 10 detik periode gempa pertama terhadap setiap hasil. Berdasarkan hasil analisis Midas menyatakan lokasi terkuat mengalami kerusakan terjadi pada tengah lantai jalan jembatan Pada titik koordinat 19 displacement terbesar terdapat pada joint 268 sebesar 1,177169 mm dan untuk U2 sebesar 0,0194 mm dan U3 sebesar 31, $763771 \mathrm{~mm}$.
\end{abstract}

Kata Kunci: Jembatan Pelengkung, Beban Gempa, Riwayat Waktu.

\begin{abstract}
The behavior of the arch bridge structure has its own peculiarities in distributing loading. The curved shape of the structure allows the structure's own weight to be transferred to the foundation as the normal compressive force without bending. the load is transferred through the semicircular structure to the abutments on either side. The curved (semicircular) design will naturally shift the load received by the floor of the bridge vehicle towards the abutment which keeps both sides of the bridge from moving sideways. Earthquake is a dominant horizontal cyclic loading of a structure. The performance of bridge structures due to the effects of earthquake loading is an important aspect that needs to be taken into account in designing and evaluating the bridge structure. The method used in this study is time history analysis. This article aims to evaluate the performance of arch bridge structures due to earthquake loads by using time-history analysis method. The results of the structure performance show that. The performance of the bridge due to the loading of the Loma prieta earthquake is generated from the period scale that has been analyzed with the 10 second period of the first earthquake for each result. Based on the results of Midas analysis, the strongest location where the damage occurs is in the middle of the bridge road. At the coordinates of 19 the largest displacement is at joint 268 of $1.177169 \mathrm{~mm}$ and for U2 of $0.0194 \mathrm{~mm}$ and $U 3$ of $31.763771 \mathrm{~mm}$.
\end{abstract}

Keywords: Arch Bridge, Earthquake Load, Time History. 


\section{PENDAHULUAN}

Di Indonesia terdapat 17 jembatan pelengkung baja dan dikenal beberapa jembatan pelengkung baja dianatara nya terdapat di Kahayan (Kalteng), Martadipura (Kaltim) dan Teluk Mesjid dan Siak III (Riau). Selain fungsi transportasi, tipe jembatan ini dipilih karena nilai estetika yang tinggi.Namun keberadaan jembatan ini tidak lepas dari permasalahan kekuatan dan kemampulayanannya. Pada tahun 2012 terjadi keruntuhan pada jembatan pelengkung di Kutai kartanegara. Hal tersebut menjadi latarbelakang dalam mengembangkan kajian kinerja struktur pada jembatan tipe ini (Lee,2008). Jembatan pelengkung adalah struktur setengah lingkaran dengan abutmen di kedua sisinya. Desain pelengkung (setengah lingkaran) secara alami akan mengalihkan beban yang diterima lantai kendaraan jembatan menuju ke abutmen yang menjaga kedua sisi jembatan agar tidak bergerak kesamping. Kemampuan ketahanan struktur untuk menahan gempa yang terjadi di Indonesia sangat berpengaruh kepada keselamatan hidup masyarakat yang sedang terjadi bencana gempa tersebut. Sebagaimana yang kita tahu bahwa di Indonesia sudah banyak terjadi gempa-gempa dahsyat salah satunya gempa aceh tahun 2004 silam dengan kekuatan gempa 9,1-9,3 magnitudo dan yang baru ini terjadi di palu Sulawesi tengah dengan banyaknya gempa-gempa susulan di daerah tersebut yg mana berkekuatan berkisar antara 6-7,4 magnitudo yang mana gempa yang terjadi tersebut sangat membahayakan struktur yang ada diatasnya.

Keruntuhan struktur akibat gempa umumnya sangat mendadak dan berbahaya bagi proses evakuasi jika tidak didesain dengan benar. Oleh karena itu, desain struktur di wilayah Indonesia harus mengacu kepada pada metode desain struktur yang telah disyaratkan di dalam SNI03-1726-2012. Di Indonesia keruntuhan struktur jembatan pelengkung terjadi di Palu. Jembatan ini baru berumur 12 tahun dann ambruk akibat gempa yang terjadi dengan 7,7 skala richter.

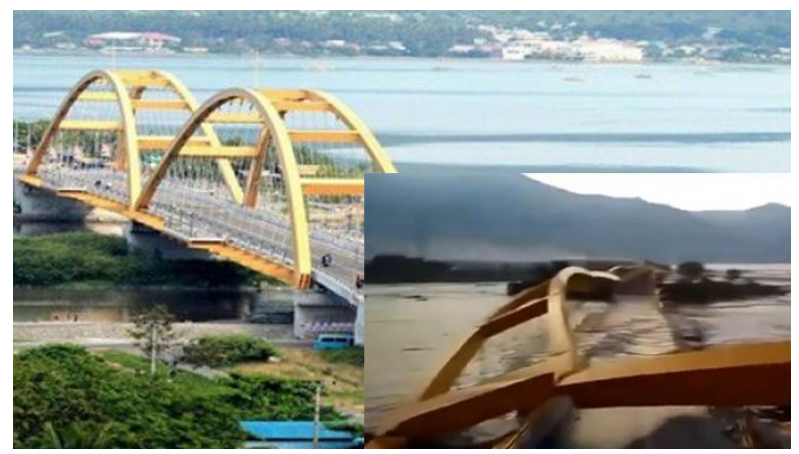

Gambar 1. Rubuhnya tiang jembatan di Palu akibat gempa

Sumber: (Tribun, 2019)
Gempa bumi Palu tahun 2018 merupakan salah satu gempa terkuat di Indonesai yang mana gempa tersebut telah merusak sarana prasarana yang ada di kota tersebut sehingga berdampak besar pada perekonomian masyarakat sekitar. Akibat banyaknya kejadian gempa tersebut yang mana perhatian terhadap struktur-struktur sudah mulai di teliti oleh beberapa penelitian dunia dan juga penelitian di Indonesia dengan mengkaji revisi peta gempa Indonesia pada SNI-03-1726-2019.

Kinerja struktur sangat diperlukan untuk mengetahui kondisi keruntuhan struktur saat terjadi gempa yang bersifat mendadak. Untuk mmperhitungkan kinerja struktur digunakan berbagai metode antara lain metode statis dan metode dinamis. Metode dinamis diantara nya adalah metode time history analisis. Metode ini menunjukkan beban gempa yang relevan terhadap waktu sehingga diperoleh kinerja struktur terhadap beban gempa dinamis.

Penelitian Mohammad Radja Nur Rizqi (2017), menyebutkan bahwa jembatan struktur pelengkung bagian upperstructure dianalisis dengan analisis time history menggunakan data gempa Hyogo Ken Nnabu (Jepang),menghasilkan bahwa tegangan pada jembatan pelengkung terbesar terjadi di gelagar dengan displacement melebihi displacement maksimum yang diizinkan. Sedangkan Artikel ini bertujuan untuk mengetahui pengaruh gempa yang terjadi pada jembatan pelengkung siak 3 serta pengaruh struktur jembatan tersebut terhadap jembatan pelengkung siak 3 dengan sampel penggunaan gempa loma prieta dengan metode time history. Analisis menggunakan Midas civil 2011.Dengan demikian perilaku struktur pada jembatan pelengkung akan lebih detail selama gempa berlangsung.

\section{METODE}

Time history adalah Percepatan,pemindahan serta Kecepatan riwayat waktu terhadap jembatan yang mengalami getaran gempa (BMS, 1993), (Lydon , 2016). Tingkat kinerja untuk analisis dinamik nonlinear (Tohidi, 2016) dapat dinyatakan sebagai operasional (B) dan tingkat kerusakan sebagai Immediate Occupancy (IO), Life Safety (LS) dan Collapse Prevention (CP) seperti yang terlihat pada Gambar.2. 


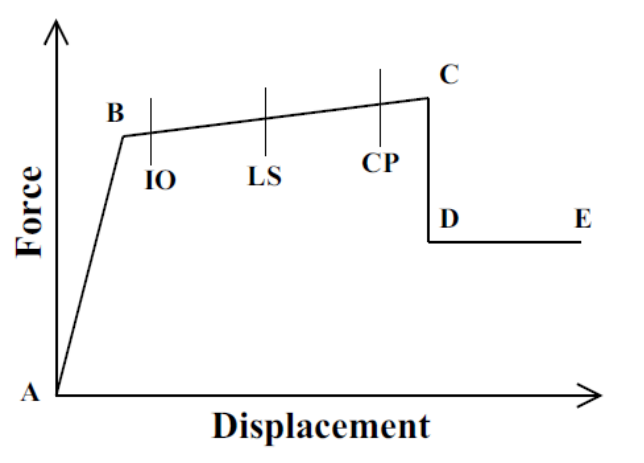

Gambar 2. Tingkat kinerja dan deformasi struktur.

Kemiringan struktur (drift) yang ditimbulkan setelah gempa bumi, "tingkat IO mempunyai sudut kemiringan sementara sebesar 1\%, tingkat LS mempunyai sudut kemiringan sementara sebesar $2 \%$ dan sudut kemiringan tetap sebesar $1 \%$ dan tingkat CP mempunyai sudut kemiringan sementara dan tetap sebesar 4\% (Neves, 2017).

Proses pemodelan jembatan pelengkung dilakukan dengan bantuan software MIDAS CIVIL 2011. Pemodelan ini dibuat menggunakan Struktur Wizard Model Arch Rib yang tersedia pada software Midas. Pemodelan jembatan menggunakan Struktur Wizard Model Arch Rib ini harus dilakukan secara bertahap. Tahap pertama, dilakukan pendefinisian panjang lengkungan atas hanger jembatan menggunakan menu arch wizard parabola 1. Diawali dengan menggambar panjang, lebar, dan bagian lengkung sesuai dengan data sekunder struktur jembatan. Jenis material, Jenis profil dan dimensi profil dimasukkan ke dalam program. Beban dan kombinasi beban di assign sesuai dengan aturan pembebanan SNI 2016.

Pada Penelitian kali ini adalah struktur jembatan pelengkung dengan panjang $120 \mathrm{~m}$ seperti Gambar 3.

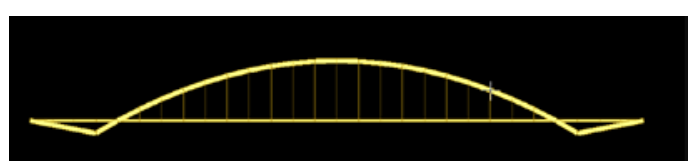

Gambar 3. struktur Jembatan Pelengkung Siak 3

Data struktur jembatan yang dianalisis tersaji dalam Tabel 1 berikut
Tabel 1. Data Struktur Jembatan

\begin{tabular}{|c|c|c|}
\hline No & Properties & Nilai Besaran \\
\hline 1 & $\begin{array}{l}\text { Tipe } \\
\text { konstruksi }\end{array}$ & Baja pelengkung \\
\hline 2 & $\begin{array}{l}\text { Diameter } \\
\text { hanger }\end{array}$ & $10 \mathrm{~cm}$ \\
\hline 3 & Lebar jalan & $7 \mathrm{~m}$ \\
\hline 4 & Lebar bahu & $1,6 \mathrm{~m}$ \\
\hline 5 & $\begin{array}{l}\text { Lebar } \\
\text { jembatan } \\
\text { seluruhnya }\end{array}$ & $10.2 \mathrm{~m}$ \\
\hline 6 & $\begin{array}{l}\text { Rangka } \\
\text { pelengkung } \\
\text { (box steel) }\end{array}$ & $\begin{array}{l}120 \times 80 \mathrm{~cm} \\
\text { tebal } 24 \mathrm{~mm}\end{array}$ \\
\hline 7 & $\begin{array}{l}\text { Rangka } \\
\text { bawah }\end{array}$ & $\begin{array}{l}60 \times 60 \mathrm{~cm} \text { tebal } \\
24 \mathrm{~mm}\end{array}$ \\
\hline 8 & $\begin{array}{l}\text { Diafragma } \\
\text { (balok } \\
\text { melintang) }\end{array}$ & $400 \times 400 \mathrm{~cm}$ \\
\hline 9 & $\begin{array}{l}\text { Girder(balok } \\
\text { memanjang) }\end{array}$ & $600 \times 600 \mathrm{~cm}$ \\
\hline 10 & Baja mutu & $\begin{array}{l}\text { JIS G } 3106 \text { SM } \\
\text { YB }\end{array}$ \\
\hline 11 & $\begin{array}{l}\text { Tegangan } \\
\text { leleh (fy) }\end{array}$ & 295 Мра \\
\hline 12 & $\begin{array}{l}\text { Tegangan } \\
\text { putus/ultimate } \\
\text { (fu) }\end{array}$ & $=490 \mathrm{Mpa}$ \\
\hline 13 & $\begin{array}{l}\text { Modulus } \\
\text { elastisitass }\end{array}$ & 200000 Mpa \\
\hline 14 & Berat jenis & $78.5 \mathrm{kN} / \mathrm{m} 3$ \\
\hline 15 & $\begin{array}{l}\text { Baja } \\
\text { mutuGrade }\end{array}$ & 490 \\
\hline 16 & $\begin{array}{l}\text { Tegangan } \\
\text { leleh }\end{array}$ & $490 \mathrm{Mpa}$ \\
\hline 17 & $\begin{array}{l}\text { Tegangan } \\
\text { putus }\end{array}$ & $610 \mathrm{Mpa}$ \\
\hline 18 & $\begin{array}{l}\text { Modulus } \\
\text { elastis }\end{array}$ & $210000 \mathrm{Mpa}$ \\
\hline 19 & Berat jenis & $78.5 \mathrm{kN} / \mathrm{m}^{3}$ \\
\hline
\end{tabular}

Analisis time history dilakukan dengan mendefinisikan fungsi riwayat waktu (Csm vs T) berdasarkan periode gempa untuk satu jembatan (Suryanita, 2015), (Darmawan, 2017) . beban gempa yang digunakan berasal dari gempa Loma Prieta yang dikonversikan terhadap beban gempa respons spektrum Pekanbaru. Selanjutnya dilakukan pengecekan kekuatan struktur. Hal ini dilakukan untuk mengetahui penampangyang mengalami overstress. Jika hasil pengecekan struktur aman, maka dilakukan pengecekan terhadap kinerja struktur yaitu displacement struktur(Chen, 2017). 


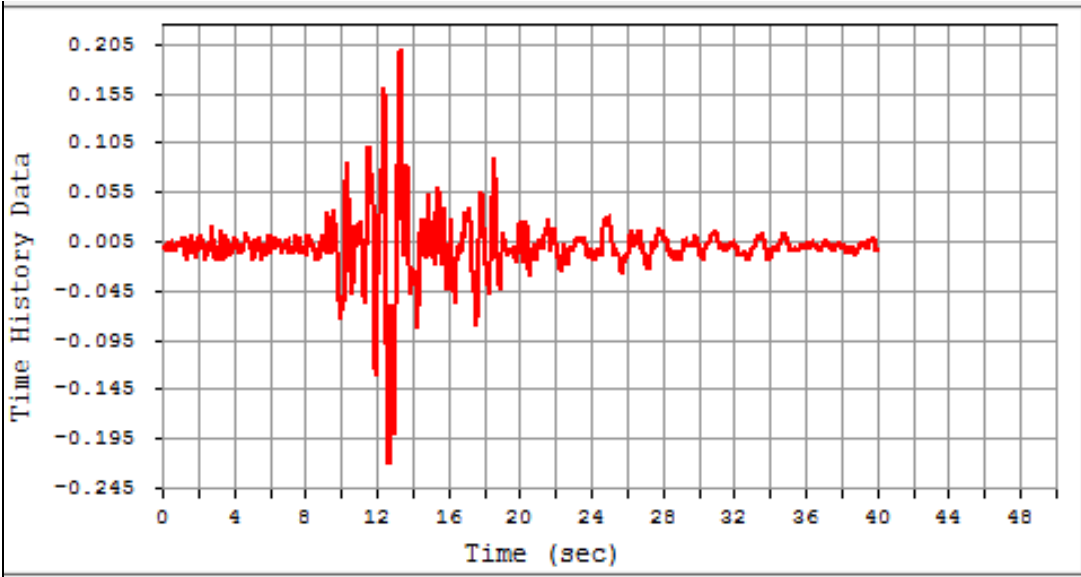

Gambar 4. Rekaman data Gempa Loma Prieta

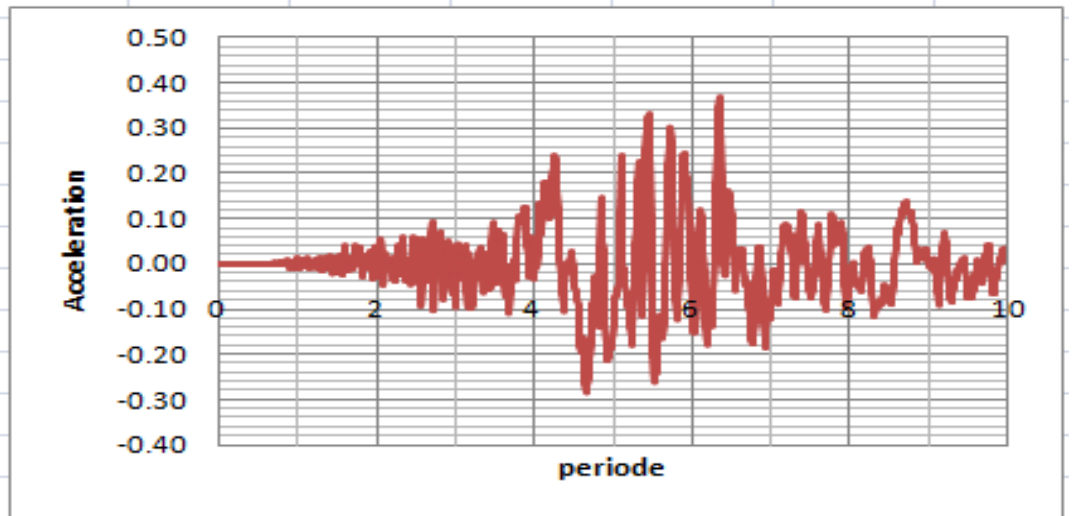

Gambar 5. Rekaman data PercepatanGempa Loma Prieta

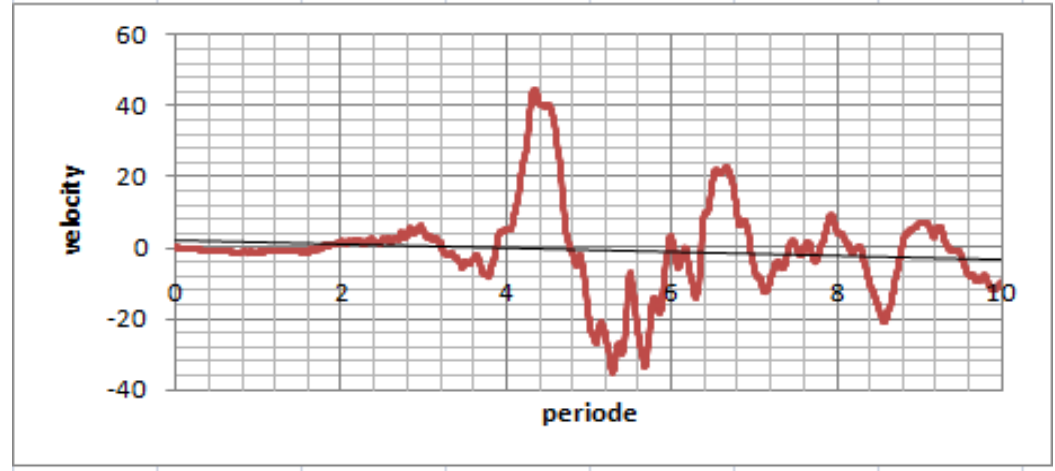

Gambar 6. Rekaman data KecepatanGempa Loma Prieta

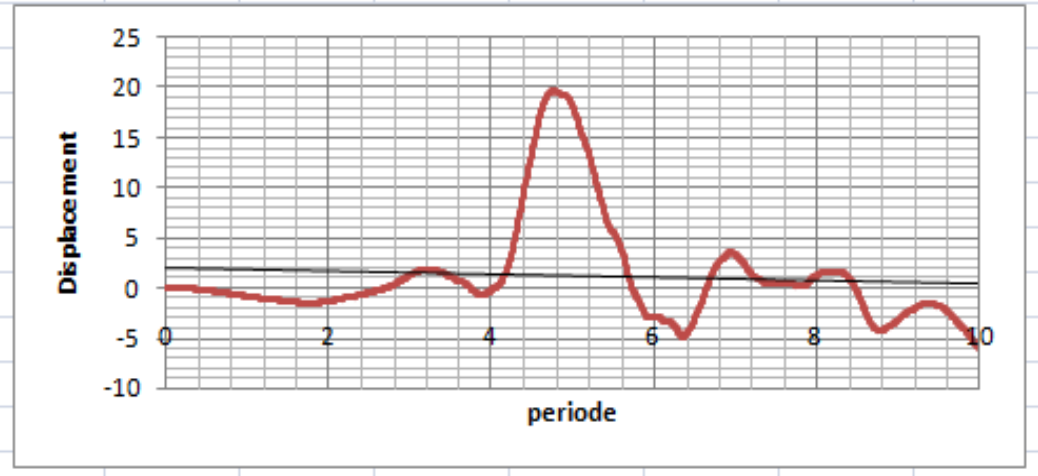

Gambar 7. Rekaman data Displacement Gempa Loma Prieta 
Berdasarkan gempa Loma Prieta dapat dilihat pada yang masing-masing menyatakan pada percepatan struktur jembatan menyatakan bahwa periode percepatan terbesar terjadi pada detik ke $6,35 \mathrm{sec}$ dengan nilai percepatan sebesar $0,3674 \mathrm{~g}$ dan kecepatan terbesar terjadi pada detik ke $4,33 \mathrm{sec}$ dengan nilai kecepatan $44,69534 \mathrm{~cm} / \mathrm{sec}$ sedangkan untuk perpindahan terbesar terjadi pada detik ke 4,76 sec dengan nilai perpindahan $19,61466 \mathrm{~cm}$.

\section{HASIL DAN PEMBAHASAN}

Kinerja jembatan akibat pembebanan gempa Loma prieta di hasilkan dari skala periode yang telah dianalisis dengan 10 detik periode gempa pertama terhadap setiap hasil. Berdasarkan hasil analisis Midas menyatakan lokasi terkuat mengalami kerusakan terjadi pada tengah lantai jalan jembatan berdasarkan gambar. Pada titik koordinat 19 displacement terbesar terdapat pada joint 268 sebesar $1,177169 \mathrm{~mm}$ dan untuk U2 sebesar 0,0194 mm dan U3 sebesar 31, 763771 $\mathrm{mm}$

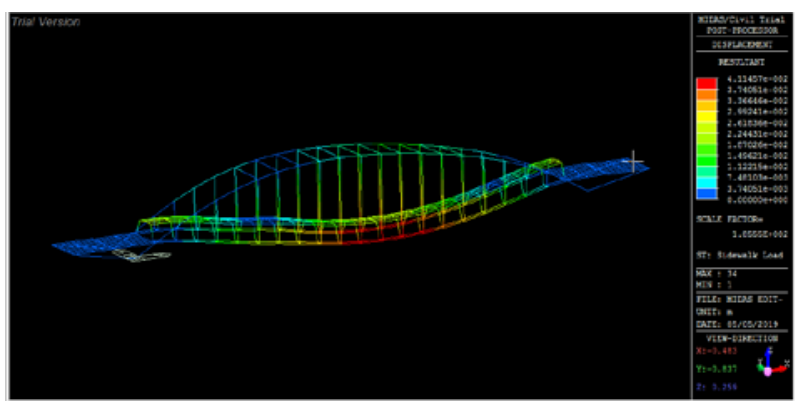

Gambar 8. Lokasi kerusakan terhadap kuat gempa Loma prieta

\section{Mode Shape Jembatan}

Mode shape yang diperoleh dari hasil analisis menunjukkan bahwa dari 12 mode shape yang ditampilkan, nilai maksimum pada Ux terdapat pada mode ke 11. Pada mode ini partisipasi masa sudah mencapai $90 \%$. Nilai ux sebesar 0,008 satuan perpindahan. Lalu pada mode shape arah y (UY) terdapat pada mode shape ketiga yaitu 0,456 satuan perpindahan. Sedangkan pada arah Z (UZ) nilai modeshape mencapai pada tahapan ke 9 yang memiliki Gerakan yang dominan naik dan turun. Sebesar 0,237 satuan perpindahan.

\section{Tegangan jembatan}

Tegangan jembatan merupakan factor yang paling penting dalam memertimbangkan kekuatan struktur jembatan tersebut (Kim, 2008). Dari masing-masing batang pada jembatan memiliki tegangan yang maksimal dimana tegangan maksimal adalah gaya aksial tarik. Diketahui bahwa batang yang mengalami tegangan tekan terbesar adalah batang gelagar pelengkung dengan besar $145.340 .804 \mathrm{~kg} / \mathrm{m}^{2}$.

\section{KESIMPULAN}

Berdasarkan analisis time history maka diperoleh detail kerusakan struktur jembatan terjadi berdasarkan periode atau waktu kekuatan gempa terhadap jembatan pelengkung dengan nilai kerusakan yang berbeda-beda.

\section{UCAPAN TERIMA KASIH}

Terima kasih kepada Kemenristek Dikti yang telah mendukung melalui program hibah Penelitian Kerja Sama Perguruan Tinggi Tahun 2019-2020. Serta Prodi Teknik Sipil Universitas Lancang Kuning.

\section{REFERENSI}

A. C. Neves, I. González, J. Leander, and R. Karoumi. (2017).Structural health monitoring of bridges: a model-free ANN-based approach to damage detection. J. Civ. Struct. Heal. Monit., vol. 7, no. 5, pp. 689-702, Nov.

Apriani, W, S. W. Megasari, W. Alrisa, and P. Loka. (2018). Penilaian Jembatan Rangka Baja Transfield Australia Dengan Metode Fracture Critical Member ( Studi Kasus: Jembatan Siak 2 Pekanbaru ). no. September, pp. 18-19.

J.-J. Lee and C.-B. Yun. (2008). Damage localization for bridges using probabilistic neural networks. KSCE J. Civ. Eng., vol. 11, no. 2, pp. 111-120.

Nur Rizqi, M. (2017). Pengaruh Gempa terhadap Perilaku Jembatan Pelengkung Sultan Muhammad Ali Abdul Jalil Muazzamyah dengan Time History Analisis. Publikasi Tugas Akhir Universitas Brawijaya Malang.

R. Suryanita. (2015) "Prediksi Kerusakan Model Jembatan Beton Bertulang Berdasarkan Mutu Beton dengan Metode Jaringan Saraf Tiruan," no. November, pp. 368-375.

M. Lydon, S. E. Taylor, D. Robinson, A. Mufti, and E. J. O. Brien. (2016). Recent developments in bridge weigh in motion (B-WIM). J. Civ. Struct. Heal. Monit., vol. 6, no. 1, pp. 69-8.

S. Kim. (2008). Experimental investigation of local damage detection on a 1/15 scale model of a suspension bridge deck. KSCE J. Civ. Eng., vol. 7, no. 4, pp. 461-468. 
S. Tohidi and Y. Sharifi. (2016). A new predictive model for restrained distortional buckling strength of half-through bridge girders using artificial neural network. KSCE J. Civ. Eng., vol. 20, no. 4, pp. 1392-1403.

Tim SNI (2019). Tata Cara Tata Cara Perencanaan Ketahanan Gempa untuk Struktur Bangunan Gedung dan Nongedung SNI-03-1726-2019
W. F. Darmawan, R. Suryanita, and Z. Djauhari, (2017). Evaluasi Kesehatan Struktur Bangunan berdasarkan Respon Dinamik Berbasiskan Data Akselerometer. Media Komun. Tek. Sipil, vol. 23, no. 2, p. 142, 2.

Z. Chen, X. Zhou, X. Wang, L. Dong, and Y. Qian,(2017). Deployment of a smart structural health monitoring system for long-span arch bridges: A review and a case study. Sensors (Switzerland), vol. 17, no. 9. 